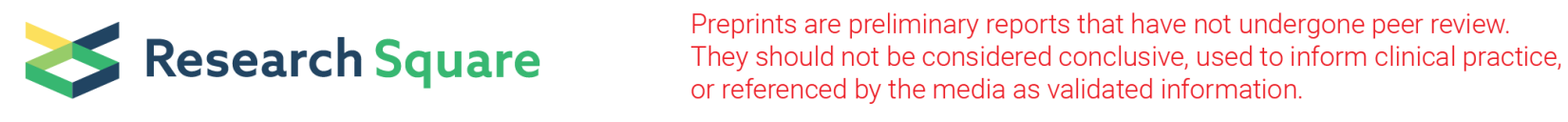

\title{
Responsiveness of Inpatient Services at the Public General Hospitals in Gaza
}

lyad Ibrahim Shaqura

Tehran University of Medical Sciences

Ebrahim Jaafaripooyan

Tehran University of Medical Sciences

Mostafa Hosseini

Tehran University of Medical Sciences

Abed El Raheem Shagora

Palestinian Ministry of Health

Ali Akbarisari ( $\square$ akbarisari@tums.ac.ir)

Tehran University o Medical Sciences, School of Public Health

\section{Research article}

Keywords: Responsiveness, Hospitals, Non-clinical care, Inpatient services, Palestine

Posted Date: January 15th, 2021

DOI: https://doi.org/10.21203/rs.3.rs-146168/v1

License: (a) (i) This work is licensed under a Creative Commons Attribution 4.0 International License. Read Full License 


\section{Abstract}

\section{Background}

This study aimed at measuring the responsiveness level of inpatient services according to patients' perspectives, and identifying the factors affecting its performance at the Gazan public general hospitals, particularly in internal medicine and surgical departments, in 2020.

\section{Methods}

It was a cross-sectional descriptive study, conducted in 5 public general hospitals in Gaza. Data were collected between October 2019 and June 2020 in a survey included 675 inpatients using an interviewed questionnaire. Data were analyzed using software SPSS 22.0 and by applying descriptive statistics, independent $t$-test and analysis of variance (ANOVA), and post hoc Scheffé test.

\section{Results}

The overall responsiveness was "above moderate", $80.15 \%$ and $80.9 \%$, for both internal medicine and surgical departments, respectively. Access to social support, confidentiality and dignity were the highest-performing domains, while, choice of provider and quality of basic amenities were the lowest. Dignity and confidentiality were the most important domains based on patients' viewpoints. Hospital type, medical department, and hospital stay in addition to the educational level, marital status, employment status, income, and insurance status were the most influential factors on the level of responsiveness and its domains.

\section{Conclusion}

The assessment of the responsiveness of inpatient services at public hospitals is useful in integrating the health system goals. Inpatient care responsiveness was satisfactory in the Gazan public hospitals, however, there is a room for further improvements. Reform strategies should be directed toward the domains of weak performance and the important ones as well. Attention should be given to the supply-side such as hospital characteristics as they significantly affect the level of responsiveness and its domains. Further research is required to carry out mixed-method studies, moreover, the non-public hospitals need to be covered.

\section{Background}

Responsiveness is a key strategic feature and stands as one of the three intrinsic goals of any health system, hence, it can act as an effective tool in evaluating its performance ${ }^{1,2}$. Improvement of responsiveness plays a substantial role in enhancing the other two goals, including health status and financial protection, and ultimately the health system performance ${ }^{3}$.

Differently from the quality of care, responsiveness represents the legitimate expectations of people in terms of non-clinical aspects of the health care services ${ }^{4,5}$. Therefore, health systems seek to ameliorate these aspects and respond to peoples' expectations in order to raise the level of satisfaction regardless of the impact of responsiveness on health status ${ }^{1,6}$. In addition, sustainment of responsiveness is not financially costy when compared to interventions related to health promotion ${ }^{7}$.

Responsiveness is expressed through two dimensions; the level and distribution. The level of responsiveness can be measured based on the perception of users, while, the distribution shows to what extent services are fairly provided to individuals in the society ${ }^{8}$. Furthermore, responsiveness is comprised of eight domains which can be classified into two categories: 1) interpersonal domains including; dignity (DIG), clear communication (CC), autonomy (AUT) and confidentiality (CON), and 2) the client-orientation domains encompassing; prompt attention (PA), access to social support networks (ASN), choice of provider (CP) and quality of basic amenities (QBA) ${ }^{8,9}$.

In the World Health Report 2000, 191 countries have been ranked according to their estimated responsiveness (level and distribution) using questionnaires developed by the World Health Organization (WHO). Some countries in the Mediterranean Region were involved such as Egypt, Jordan, Syria, Lebanon, Iran and Qatar, and were ranked 102, 85, 70, 55, 100, and 27, respectively ${ }^{8}$. State of Palestine was not among the targeted countries in that study.

The Palestinian health system embraces five health care providers. The Ministry of Health $(\mathrm{MOH})$ is the main provider which owns and administers 471 primary healthcare centers and 26 public hospitals in both West Bank and Gaza Strip (GS). Of the 26 hospitals, there 
are 13 in the GS containing about 2,240 active beds, in other words, 11.4 bed per 10,000 inhabitants. Out of 13, 7 hospitals in the GS are general as they provide internal medicine and surgical inpatient services. The active beds in internal medicine and surgical departments stand for $52 \%$ of the total active beds at the public hospitals in GS ${ }^{10,11}$.

Generally, there is no focus on the responsiveness as a core goal of the Palestinian health system. Since there is a paucity of studies in the literature on measuring the level of responsiveness for any types of health services at any level in Palestine, this study was the first in the Palestinian health context which aimed at measuring the responsiveness level of inpatient services according to patients' perspectives, and identifying the factors affecting its performance at the Gazan public general hospitals, particularly in internal medicine and surgical departments in 2020.

\section{Methods \\ Study setting}

This cross-sectional descriptive survey was conducted in the internal medicine and surgical departments at the Gazan public general hospitals in 2020. Anonymously, the included hospitals in this study which locate in the five governorates, were given the codes from A to E. Hospital A (large and non-educational), B (central and educational complex), C (large and non-educational), D (central and educational complex) and $\mathrm{E}$ (central and educational large hospital). It is noteworthy that all hospitals in our study deliver a similar range of services, and this can significantly reduce the case-mix bias and make the comparison more feasible.

\section{Sampling and sample size}

Multi-staged sampling has been used to select the study participants. Firstly and based on the annual admissions in the investigated departments, the total sample size was calculated for both internal medicine and surgical departments by applying the formula below, 381 and 382 participants, respectively.

$\mathrm{n}=\mathrm{N} * \mathrm{X} /(\mathrm{X}+\mathrm{N}-1)$

Where, $X=Z_{a / 2}{ }^{2}{ }^{*} *(1-p) / M O E^{2}$, and $Z_{a / 2}$ is the critical value of the Normal distribution at $a / 2$ (e.g. for a confidence level of $95 \%$, $a$ is 0.05 and the critical value is 1.96), MOE is the margin of error, $\mathrm{p}$ is the sample proportion, and $\mathrm{N}$ is the population size ${ }^{12}$. N in the current study was 39,000 and 49,000 admissions in internal medicine and surgical departments, respectively.

Secondly, proportional sampling was performed to determine the sample in each hospital in accordance to the number of installed beds in the abovementioned departments. Next, another proportional sampling was carried out according to the number of beds in male and female wards at the same department. Finally, participants were selected randomly after confirming the inclusion criteria; a) inpatients admitted in the departments under study, b) patients whose age $\geq 16$ year old, and c) patients who have stayed in the department for 2 days or more. On the other hand, patients hospitalized in intensive care units, cardiology care units, and obstetrics departments have been excluded.

\section{Data collection}

By modifying the WHO questionnaire, a pre-tested interview-based questionnaire was developed. The English version has been translated into Arabic by two professional persons, then back-translation from Arabic to English has been undertaken once again by another two professionals. Content validity, addition and elimination of items to modify the original questionnaire have been performed by 12 experts in the field from academia and health sector. A pilot study of 150 patients has been conducted to check the reliability of the modified questionnaire which covers two main parts; 1) the patients' sociodemographic characteristics including: age, sex, marital status, educational level, occupational status, income, insurance, hospital stay, in addition to the hospital of admission and medical department, and 2) the perception of patients toward the eight domains that encompass 37 items on a 4-point Likert scale ( 1 = highly disagree, 2 = disagree, $3=$ agree, and 4 = highly agree). The idea of adopting even-numbered response categories is to have a balanced number of positive and negative options as well as prevent giving people an "out" and makes them more thoughtful in their responses ${ }^{13}$. The number of items for each domain was as follow: DIG ( 5 items), CC ( 5 items), AUT (4 items), CON ( 3 items), PA (4 items), ASN (4 items), CP (3 items), QBA (8 items), and one question to assess the importance of domains on a (0-10) scale. Based on standardized items, Cronbach's alpha was used for measuring the internal consistency of the abovementioned eight domains, and the related values were; $0.79,0.82,0.70,0.76,0.78,0.86,0.81$, and 0.87 , respectively. Data have been collected in the 
period from October 2019 up to June 2020. Of the 760 needed participants, 675 participants have responded and completed the interview-based questionnaire, hence, the response rate was about $88.5 \%$.

\section{Data analysis}

Subsequent to assessing data normality by the two-sample Kolmogorov-Smirnov test, data were analyzed by applying descriptive statistics (frequency, percentage, mean, and standard deviation), independent $t$-test and analysis of variance (ANOVA) using SPSS 22.0 (SPSS Inc., Chicago, IL, USA). A Scheffé post-hoc test was also employed to compare between groups' means in ANOVA. For all tests, results was regarded statistically significant when a $p$ value $\leq 0.05$. After calculating the average for each domain score, the weighted mean score per each was then determined as recommended in the WHO methodology ${ }^{8}$. The percentage scores (\%) used in Tamimi study have been adopted as references for evaluating responsiveness and its domains; (20-36\% very low), (36.1-52\% low), (52.1-68\% moderate), (68.1-84\% above moderate) and (84.1-100\% high) ${ }^{14}$.

\section{Ethical considerations}

Ethical approvals for this study were granted by the Vice-Chancellor in Research Affairs- Tehran University of Medical Sciences (IR. TUMS. VCR. REC. 1398.360), in addition, the study was submitted to the ethics committee local to our study in Palestine, Helsinki committee in the Palestinian Health Research Council, approved and given the code: (PHRC/HC/959/19). Moreover, informed consents were verbally obtained out from all participants, and confidentiality was assured as well.

\section{Results}

\section{Participant characteristics}

As illustrated in Table 1, 675 respondents have completed the study questionnaire. Of them, 35\% were hospitalized at hospital B; the average age was 45.3 years (SD $=18.287) ; 54.5 \%$ were male; $74.2 \%$ married; $26.5 \%$ were residents in Khanyounis governorate; $51.4 \%$ were holders of bachelor degree or higher; $44.9 \%$ unemployed; $38.9 \%$ with monthly income $\leq 1000$ New Israeli Shekel (NIS) (1 USD = $3.35 \mathrm{NIS}$ at the time of writing this manuscript); $66.8 \%$ were enrollees in governmental insurance plan; $53.9 \%$ admitted at surgical departments; and $46.1 \%$ hospitalized for 3 to 5 days. 
Table 1

Sociodemographic characteristics of study participants

\begin{tabular}{|c|c|c|c|}
\hline Variable & & Number (n) & Percentage (\%) \\
\hline \multirow[t]{5}{*}{ Hospital } & $A$ & 105 & 15.6 \\
\hline & B & 236 & 35.0 \\
\hline & C & 71 & 10.5 \\
\hline & D & 113 & 16.7 \\
\hline & E & 150 & 22.2 \\
\hline \multirow[t]{8}{*}{ Age (years) } & $16-20$ & 49 & 7.30 \\
\hline & $21-30$ & 119 & 17.6 \\
\hline & $31-40$ & 135 & 20.0 \\
\hline & $41-50$ & 126 & 18.7 \\
\hline & $51-60$ & 104 & 15.4 \\
\hline & $61-70$ & 73 & 10.8 \\
\hline & $\geq 71$ & 69 & 10.2 \\
\hline & \multicolumn{3}{|c|}{ Mean $=45.296 \mathrm{SD}=18.287$ years } \\
\hline \multirow[t]{2}{*}{ Sex } & Male & 368 & 54.5 \\
\hline & Female & 307 & 45.5 \\
\hline \multirow[t]{4}{*}{ Marital status } & Single & 99 & 9.0 \\
\hline & Married & 501 & 2.1 \\
\hline & Divorced & 14 & 74.2 \\
\hline & Widow & 61 & 14.7 \\
\hline \multirow[t]{5}{*}{ Educational level } & Illiterate & 65 & 9.6 \\
\hline & Basic & 80 & 11.9 \\
\hline & Secondary & 144 & 21.3 \\
\hline & Vocational & 39 & 5.8 \\
\hline & BSc or higher & 347 & 51.4 \\
\hline \multirow[t]{5}{*}{ Occupational status } & Governmental & 215 & 31.9 \\
\hline & Non-governmental & 23 & 3.4 \\
\hline & UNRWA* & 42 & 6.2 \\
\hline & Private & 92 & 13.6 \\
\hline & Unemployed & 303 & 44.9 \\
\hline \multirow[t]{5}{*}{ Monthly income (NIS) } & $\leq 1000$ & 204 & 38.9 \\
\hline & $1001-1500$ & 114 & 21.7 \\
\hline & $1501-2000$ & 63 & 12.0 \\
\hline & $2001-2500$ & 45 & 8.6 \\
\hline & $\geq 2501$ & 99 & 18.9 \\
\hline
\end{tabular}

*UNRWA: United Nations for Working and Relief Agency 


\begin{tabular}{|c|c|c|c|}
\hline Variable & & Number (n) & Percentage (\%) \\
\hline & \multicolumn{3}{|c|}{ Mean $=1581.066 \mathrm{SD}=1132.717 \mathrm{NIS}$} \\
\hline \multirow[t]{6}{*}{ Insurance type } & Governmental & 451 & 66.8 \\
\hline & Military & 12 & 1.8 \\
\hline & Labor & 60 & 8.9 \\
\hline & Social affairs & 112 & 16.6 \\
\hline & Private & 36 & 5.3 \\
\hline & Uninsured & 4 & 0.6 \\
\hline \multirow[t]{2}{*}{ Medical department } & Internal Medicine & 311 & 46.1 \\
\hline & Surgical & 364 & 53.9 \\
\hline \multirow[t]{4}{*}{ Hospital stay (days) } & $1-2$ & 254 & 37.6 \\
\hline & $3-5$ & 311 & 46.1 \\
\hline & $\geq 6$ & 110 & 16.3 \\
\hline & \multicolumn{3}{|c|}{ Mean $=3.979 \mathrm{SD}=4.273$ days } \\
\hline
\end{tabular}

\section{Scores of the responsiveness domains}

Table 2 shows the findings for both overall responsiveness and the eight domains of inpatient services in the departments under study. The overall responsiveness was "above moderate", $80.15 \%$ and $80.9 \%$, at internal medicine and surgical departments, respectively. ASN was the highest in its performance level (98\%), and ranked as "high" based on the study reference values. This was followed by CON, DIG and CC based on participants' opinions in both internal medicine and surgical departments, whilst, CP and QBA were evaluated lowest in both departments and their levels ranged from 58 to $62 \%$ (moderate). Drawing on patients' viewpoints in both departments, DIG and CON were the most important domains, whereas, QBA and CP were reported 6th and 8th, respectively. 
Table 2

Responses of participants on responsiveness domains

\begin{tabular}{|c|c|c|c|c|c|c|c|c|c|c|c|c|}
\hline \multirow[t]{2}{*}{$\#$} & \multirow[t]{2}{*}{ Domain } & \multirow[t]{2}{*}{ Wt. } & \multicolumn{5}{|c|}{ Internal medicine } & \multicolumn{5}{|c|}{ Surgical department } \\
\hline & & & Mean & SD & $\begin{array}{l}\text { Wt. } \\
\text { score }\end{array}$ & $\begin{array}{l}\text { Wt. P. } \\
(\%)\end{array}$ & Importance & Mean & SD & $\begin{array}{l}\text { Wt. } \\
\text { score }\end{array}$ & $\begin{array}{l}\text { Wt. P. } \\
\text { (\%) }\end{array}$ & Importance \\
\hline 1 & Dignity & 12.5 & 3.611 & 0.461 & 11.30 & 90.40 & 2 & 3.556 & 0.417 & 11.11 & 88.88 & 1 \\
\hline 2 & $\begin{array}{l}\text { Clear } \\
\text { communication }\end{array}$ & 12.5 & 3.428 & 0.466 & 10.70 & 85.60 & 7 & 3.409 & 0.487 & 10.65 & 85.20 & 3 \\
\hline 3 & Autonomy & 12.5 & 3.141 & 0.478 & 9.80 & 78.40 & 5 & 3.261 & 0.511 & 10.20 & 81.60 & 5 \\
\hline 4 & Confidentiality & 12.5 & 3.695 & 0.321 & 11.55 & 92.40 & 1 & 3.650 & 0.436 & 11.40 & 91.20 & 2 \\
\hline 5 & $\begin{array}{l}\text { Prompt } \\
\text { attention }\end{array}$ & 20 & 3.042 & 0.652 & 15.20 & 76 & 3 & 3.079 & 0.605 & 15.38 & 76.90 & 4 \\
\hline 6 & $\begin{array}{l}\text { Access to } \\
\text { social support } \\
\text { networks }\end{array}$ & 10 & 3.914 & 0.209 & 9.80 & 98 & 4 & 3.925 & 0.234 & 9.80 & 98 & 7 \\
\hline 7 & $\begin{array}{l}\text { Choice of care } \\
\text { provider }\end{array}$ & 5 & 2.409 & 0.601 & 3 & 60 & 8 & 2.459 & 0.728 & 3.08 & 61.60 & 8 \\
\hline 8 & $\begin{array}{l}\text { Quality of basic } \\
\text { amenities }\end{array}$ & 15 & 2.350 & 0.613 & 8.80 & 58.67 & 6 & 2.476 & 0.572 & 9.28 & 61.86 & 6 \\
\hline \multicolumn{2}{|c|}{$\begin{array}{l}\text { Overall } \\
\text { responsiveness }\end{array}$} & 100 & \multicolumn{5}{|c|}{80.15} & \multicolumn{5}{|c|}{80.90} \\
\hline
\end{tabular}

Factors affecting responsiveness

Hospital of admission, age, marital status, educational level, occupational status, income, insurance, medical department, and length of stay have led to statistically significant differences in the level of total responsiveness as well as some domains (Table 3). Scheffé test has investigated the statistically significant effect of certain groups on responsiveness (Table 4). Hospital of admission was the most influential factor as it revealed statistically significant differences in responsiveness among the investigated hospitals (Table 5). The scores of QBA have demonstrated remarkable variations with respect to different groups within the examined variables, followed by PA, CC and AUT, ASN and CP, and at last, DIG and CON (Table 4). 
Table 3

Effect of patients characteristics on responsiveness and its domains

\begin{tabular}{|c|c|c|c|}
\hline Variable & Responsiveness domain & $\mathbf{F}$ & Significance \\
\hline Hospital of admission & Overall responsiveness and all domains & - & 0.000 \\
\hline \multirow[t]{6}{*}{ Age } & Clear communication & 2.692 & 0.014 \\
\hline & Autonomy & 2.762 & 0.012 \\
\hline & Prompt attention & 3.858 & 0.001 \\
\hline & Choice of provider & 2.554 & 0.019 \\
\hline & Quality of basic amenities & 4.845 & 0.000 \\
\hline & Overall responsiveness & 5.229 & 0.000 \\
\hline \multirow[t]{3}{*}{ Marital status } & Access to social networks & 4.957 & 0.002 \\
\hline & Quality of basic amenities & 5.461 & 0.001 \\
\hline & Overall responsiveness & 3.120 & 0.026 \\
\hline \multirow[t]{7}{*}{ Educational level } & Clear communication & 3.992 & 0.003 \\
\hline & Autonomy & 3.512 & 0.008 \\
\hline & Prompt attention & 8.072 & 0.000 \\
\hline & Access to social networks & 3.882 & 0.004 \\
\hline & Choice of provider & 2.433 & 0.046 \\
\hline & Quality of basic amenities & 42.397 & 0.000 \\
\hline & Overall responsiveness & 28.929 & 0.000 \\
\hline \multirow[t]{5}{*}{ Occupational status } & Clear communication & 2.876 & 0.022 \\
\hline & Prompt attention & 3.807 & 0.005 \\
\hline & Choice of provider & 2.893 & 0.022 \\
\hline & Quality of basic amenities & 29.457 & 0.000 \\
\hline & Overall responsiveness & 23.151 & 0.000 \\
\hline \multirow[t]{6}{*}{ Monthly income } & Clear communication & 2.755 & 0.027 \\
\hline & Autonomy & 7.975 & 0.000 \\
\hline & Prompt attention & 9.271 & 0.000 \\
\hline & Choice of provider & 17.379 & 0.000 \\
\hline & Quality of basic amenities & 42.476 & 0.000 \\
\hline & Overall responsiveness & 18.178 & 0.000 \\
\hline \multirow[t]{6}{*}{ Insurance type } & Dignity & 3.671 & 0.003 \\
\hline & Clear communication & 2.240 & 0.049 \\
\hline & Confidentiality & 5.335 & 0.000 \\
\hline & Access to social networks & 5.456 & 0.000 \\
\hline & Quality of basic amenities & 18.242 & 0.000 \\
\hline & Overall responsiveness & 8.905 & 0.000 \\
\hline Medical department & Autonomy & -3.151 & 0.002 \\
\hline
\end{tabular}

Page 8/16 


\begin{tabular}{|llll|}
\hline Variable & Responsiveness domain & F & Significance \\
\hline Quality of basic amenities & -2.745 & 0.006 \\
\hline Hospital stay & Overall responsiveness & -2.136 & 0.033 \\
\hline Clear communication & 5.793 & 0.003 \\
\hline Autonomy & 5.411 & 0.005 \\
\hline Prompt attention & 11.266 & 0.000 \\
\hline Choice of provider & 4.856 & 0.008 \\
\hline Quality of basic amenities & 38.905 & 0.000 \\
\hline Overall responsiveness & 36.486 & 0.000 \\
\hline
\end{tabular}


Table 4

Scheffé test for differences in responsiveness related to patients' characteristics

\begin{tabular}{|c|c|c|c|}
\hline Domain & Variable & $F$ & Significance \\
\hline \multirow{2}{*}{$\begin{array}{l}\text { Clear communication } \\
\text { Autonomy }\end{array}$} & $\geq 70-(40-50)$ years old & 0.255 & 0.045 \\
\hline & $\geq 70-(40-50)$ years old & 0.292 & 0.017 \\
\hline Prompt attention & $\geq 70-(40-50)$ years old & 0.358 & 0.021 \\
\hline Quality of basic amenities & $\geq 70-(40-50)$ years old & 0.400 & 0.002 \\
\hline \multirow{2}{*}{$\begin{array}{l}\text { Access to social networks } \\
\text { Quality of basic amenities }\end{array}$} & Married - Divorced & 0.202 & 0.010 \\
\hline & Married - Widow & -0.227 & 0.045 \\
\hline \multirow{6}{*}{$\begin{array}{l}\text { Clear communication } \\
\text { Prompt attention } \\
\text { Quality of basic amenities }\end{array}$} & Illiterate - BSc or higher & 3.992 & 0.003 \\
\hline & Illiterate - BSc or higher & 3.512 & 0.008 \\
\hline & BSc or higher - Illiterate & -0.441 & 0.000 \\
\hline & BSc or higher - Basic education & -0.531 & 0.000 \\
\hline & BSc or higher - Secondary & -0.546 & 0.000 \\
\hline & BSc or higher - Vocational & -0.611 & 0.000 \\
\hline \multirow{5}{*}{$\begin{array}{l}\text { Prompt attention } \\
\text { Quality of basic amenities }\end{array}$} & Unemployed - Governmental & 0.187 & 0.023 \\
\hline & Unemployed - Governmental & 0.479 & 0.000 \\
\hline & Unemployed - Nongovernmental & 0.502 & 0.001 \\
\hline & Unemployed - UNRWA & 0.534 & 0.000 \\
\hline & Unemployed - Private & 0.323 & 0.000 \\
\hline \multirow{14}{*}{$\begin{array}{l}\text { Autonomy } \\
\text { Prompt attention } \\
\text { Choice of provider } \\
\text { Quality of basic amenities }\end{array}$} & $\leq 1000-(1501-2000)$ NIS* $^{*}$ & 0.286 & 0.002 \\
\hline & $\leq 1000-(2001-2500) \mathrm{NIS}$ & 0.333 & 0.002 \\
\hline & $\leq 1000->2500 \mathrm{NIS}$ & 0.199 & 0.022 \\
\hline & $\leq 1000-(1501-2000) \mathrm{NIS}$ & 0.428 & 0.000 \\
\hline & $\leq 1000-(2001-2500) \mathrm{NIS}$ & 0.394 & 0.003 \\
\hline & $\leq 1000->2500 \mathrm{NIS}$ & 0.265 & 0.012 \\
\hline & $\leq 1000-(1001-1500) \mathrm{NIS}$ & 0.272 & 0.007 \\
\hline & $\leq 1000-(1501-2000)$ NIS & 0.509 & 0.000 \\
\hline & $\leq 1000-(2001-2500) \mathrm{NIS}$ & 0.596 & 0.000 \\
\hline & $\leq 1000->2500 \mathrm{NIS}$ & 0.454 & 0.000 \\
\hline & $\leq 1000-(1001-1500) \mathrm{NIS}$ & 0.303 & 0.000 \\
\hline & $\leq 1000-(1501-2000) \mathrm{NIS}$ & 0.680 & 0.000 \\
\hline & $\leq 1000-(2001-2500)$ NIS & 0.653 & 0.000 \\
\hline & $\leq 1000->2500 \mathrm{NIS}$ & 0.604 & 0.000 \\
\hline \multirow{3}{*}{$\begin{array}{l}\text { Dignity } \\
\text { Confidentiality } \\
\text { Access to social networks }\end{array}$} & Governmental - Labor & 0.235 & 0.009 \\
\hline & Governmental - Labor & 0.225 & 0.003 \\
\hline & Governmental - Labor & 0.141 & 0.001 \\
\hline
\end{tabular}

Page $10 / 16$ 


\begin{tabular}{|c|c|c|c|}
\hline Domain & Variable & $\mathbf{F}$ & Significance \\
\hline & Governmental - Labor & -0.516 & 0.000 \\
\hline & Governmental - Social affairs & -0.440 & 0.000 \\
\hline Autonomy & Internal medicine - Surgical & -3.151 & 0.002 \\
\hline Quality of basic amenities & Internal medicine - Surgical & -2.745 & 0.006 \\
\hline \multirow{9}{*}{$\begin{array}{l}\text { Clear communication } \\
\text { Autonomy } \\
\text { Prompt attention } \\
\text { Choice of provider } \\
\text { Quality of basic amenities }\end{array}$} & $\geq 6-(1-2)$ days & 0.158 & 0.014 \\
\hline & $\geq 6-(3-5)$ days & 0.174 & 0.004 \\
\hline & $\geq 6-(1-2)$ days & 0.178 & 0.007 \\
\hline & $\geq 6-(3-5)$ days & 0.161 & 0.014 \\
\hline & $\geq 6-(1-2)$ days & 0.326 & 0.000 \\
\hline & $\geq 6-(3-5)$ days & 0.278 & 0.000 \\
\hline & $\geq 6-(3-5)$ days & 0.404 & 0.008 \\
\hline & $\geq 6-(1-2)$ days & 0.532 & 0.000 \\
\hline & $\geq 6-(3-5)$ days & 0.505 & 0.000 \\
\hline
\end{tabular}


Table 5

Scheffé test for differences in responsiveness related to hospital of admission

\begin{tabular}{|c|c|c|c|}
\hline Domain & Variable & $F$ & Significance \\
\hline \multirow[t]{3}{*}{ Dignity } & Hospital E - Hospital B & 0.188 & 0.001 \\
\hline & Hospital E - Hospital C & 0.489 & 0.000 \\
\hline & Hospital E - Hospital D & 0.393 & 0.000 \\
\hline \multirow[t]{4}{*}{ Clear communication } & Hospital E - Hospital A & 0.379 & 0.000 \\
\hline & Hospital E - Hospital B & 0.452 & 0.000 \\
\hline & Hospital E - Hospital C & 0.564 & 0.000 \\
\hline & Hospital E - Hospital D & 0.379 & 0.000 \\
\hline \multirow[t]{4}{*}{ Autonomy } & Hospital E - Hospital A & 0.433 & 0.000 \\
\hline & Hospital E - Hospital B & 0.462 & 0.000 \\
\hline & Hospital E - Hospital C & 0.439 & 0.000 \\
\hline & Hospital E - Hospital D & 0.339 & 0.000 \\
\hline \multirow[t]{4}{*}{ Confidentiality } & Hospital E - Hospital A & 0.282 & 0.000 \\
\hline & Hospital E - Hospital B & 0.312 & 0.000 \\
\hline & Hospital E - Hospital C & 0.641 & 0.000 \\
\hline & Hospital E - Hospital D & 0.606 & 0.000 \\
\hline \multirow[t]{4}{*}{ Prompt attention } & Hospital E - Hospital A & 0.768 & 0.000 \\
\hline & Hospital E - Hospital B & 0.832 & 0.000 \\
\hline & Hospital E - Hospital C & 0.895 & 0.000 \\
\hline & Hospital E - Hospital D & 0.572 & 0.000 \\
\hline Access to social networks & Hospital E - Hospital D & 0.360 & 0.000 \\
\hline \multirow[t]{4}{*}{ Choice of provider } & Hospital E - Hospital A & 1.208 & 0.000 \\
\hline & Hospital E - Hospital B & 1.058 & 0.000 \\
\hline & Hospital E - Hospital C & 1.475 & 0.000 \\
\hline & Hospital E - Hospital D & 1.151 & 0.000 \\
\hline \multirow[t]{3}{*}{ Quality of basic amenities } & Hospital E - Hospital A & 0.920 & 0.000 \\
\hline & Hospital E - Hospital B & 0.911 & 0.000 \\
\hline & Hospital E - Hospital D & -0.147 & 0.027 \\
\hline
\end{tabular}

\section{Discussion}

This study aimed to assess the responsiveness of inpatient services at the Gazan public general hospitals, and to identify the most influential factors on its performance level. Traditionally, assessment of both performance and importance when studying responsiveness of any health system are considered ${ }^{2,15}$.

In the current study, responsiveness level was above moderate 'about $80 \%$ ' which seems satisfactory for the Palestinian hospital system, interestingly, it was better than responsiveness level in some other studies such as Javadi et al (48\%) ${ }^{16}$, Ebrahimipour et al $(53.2 \%){ }^{17}$, and Mohammadi and Koorosh (58.4\%) ${ }^{18}$. Factors such as hospital of admission, age, marital status, educational level, income, insurance, medical department, and hospital stay have significantly affected the responsiveness level. These findings were 
consistent with some previous studies in the literature ${ }^{7,17,19-24}$, and this might draw the attention of policymakers to check in such factors when planning for responsiveness improvement.

DIG, CON and PA were the most important domains in both departments, while, CP and QBA were the least. This was, to some extent, in line with some studies in the literature ${ }^{16,25,26}$. This might be attributed to the importance of respect, privacy and receiving rapid and timely care when needed, on the other hand, people realize that they have no chance to choose their providers based on the policy of the $\mathrm{MOH}$, accordingly, they underestimate the importance of CP. CC and ASN were the seventh and fourth important domains for patients in internal departments, but the third and seventh in surgical departments, respectively. Generally, working environment and the procedures employed may differ from one department to another, in addition, these results necessitate the focus on some domains more than others.

Furthermore, ASN, CON, DIG, CC, AUT and PA were the highest-performing domains in both departments, respectively, whilst, CP and QBA were the least. Well-scheduled visits for escorts and relatives, and the value of social support in the view of married persons might justify the highest level of ASN as stated in two previous studies ${ }^{16,17}$. For $\mathrm{CP}$, generally, the Palestinian health system does not allow patients to choose their providers, rather, patients should receive the health services in specific places according to the geographical distribution and place of residency due to the shortage of specialists and the potentially consequent bias. The best performing item in AUT domain was that related to the informed consent prior to any medical or surgical procedure (about $90 \%$ ), and this can be due to the rules and regulations which mandate filling out certain forms accordingly. This corresponds the findings involved in other studies 13,17,22. In CON domain, the privacy of information and medical records was the most paramount for patients in both departments, and this was consistent with some former studies ${ }^{18,27,28}$. It should be noted that the siege and related financial hardship and economic decline, staff burnout, shortages of in healthcare workforce, and the problem in remuneration system may adversely affect the staff commitment, and ultimately reduced responsiveness performance, particularly PA domain 27,29 .

Type of hospital was one of the most influential factors on domains' performance. Except for QBA, hospital E was the best-performing among all hospitals based on patients' perspectives, however, hospital D was better in its performance in QBA. E is a large, teaching and referral hospital which was well-established, administered and operated by European staff for years. Moreover, well-qualified specialists, rules and regulations, management practices, sophisticated electronic system, educational programs, and less crowding play a crucial role in raising awareness of health care providers about non-clinical aspects of care. The information system in such hospitals produces rich data and leads to enhancing the provider-client relationship ${ }^{20,30}$. The recent construction and maintenance activities, and the newly founded and well-facilitated buildings have contributed in ameliorating QBA in departments under study in hospital D. Conversely, lack of rooms' space, electricity cutoffs in the absence of alternatives such as diesel, have decreased level of QBA at the Nigerian public hospitals ${ }^{20}$. In their study, Mosallam et al discovered that rooms shared by several patients without curtains have adversely affected the CON performance at the public hospitals.

Elderly patients in this study ( $\geq 70$ years old) showed higher levels of responsiveness, CC, AUT, PA and QBA, and this was consistent with Peltzer et al study ${ }^{21}$. These findings could be due to the cultural respect to elderly people which gives them the advantage in all domains. Low expectations and insufficient awareness level, in addition to the information asymmetry between providers and loweducated patients might account for the better performance in responsiveness, CC, PA and QBA. In the same vein, jobless patients and those of low income gave higher performance ratings for PA and QBA, and AUT, PA, CP and QBA, respectively. This also reflects the low ceiling of expectations, the lower social status they may feel, and the conditions they live as well. However, these results could give a positive impression but might mask some defects in the system as stated by Mohammed et al ${ }^{30}$.

Although there was notable differences in the levels of DIG, CON, ASN and QBA according to the insurance type, this might be referred to reasons other than the type itself that is because the Palestinian health system does not limit the accessibility of uninsured persons to inpatient services. For that, there is a way to enable those uninsured patients and those holders of expired insurance to receive the health care service and sign a commitment to pay for the insurance later on. Nonetheless, the expectations of enrollees in the labor or social insurance plans regarding QBA may justify their better perspective about this domain.

Patients admitted to surgical departments reported higher performance for AUT and QBA, and these differences were statistically significant. The clear information and consultation on treatment alternatives in surgical departments, moreover, the quality of basic services related to rooms and facilities in these departments may owe for the better-off performance therein. The findings in the present study were consistent with those of previous studies ${ }^{21,24,30}$. For hospital stay, it was obvious that those patients who have 
stayed for 6 days or more showed higher performance levels in CC, AUT, PA, CP and QBA. The friendly atmosphere which can be developed with time between those patients and the staff, in addition to the paternalistic behavior ${ }^{30}$ are potential explanations for this result.

$\mathrm{CP}$ was selected as the least important domain according to patients from both departments. Furthermore, $\mathrm{CP}$ and QBA were the lowest domains in performance (about $60 \%$ ). CP performance was significantly affected by hospital type (hospital E), income ( $\leq 1000$ NIS) and hospital stay ( $\geq 6$ days). However, there is a restricted room in hospital $\mathrm{E}$ for the patient to choose his provider as this hospital is relatively less crowded and has plenty of well-qualified specialists. Giving more attention to CP is expected to raise performance of the overall responsiveness ${ }^{13,18,20,27}$.

\section{Conclusion}

The assessment of the responsiveness of inpatient health care services at public hospitals is useful in integrating the health system goals. The overall responsiveness was about $80 \%$, above moderate, and is viable for further improvement. The domains QBA, CP and PA were highlighted as crucial areas to ameliorate the perceived responsiveness of healthcare services. The gap between importance and performance of CC and ASN in internal medical and surgical departments, respectively, should be addressed. Reform strategies should be directed toward all domains, considering their weight and effect in promoting the total responsiveness. Attention should be also given to patients' as well as hospital characteristics in order to elucidate a comprehensive picture about responsiveness. Further researches of mixed-method design are required to obtain more rigorous results. Extensive studies are also needed to cover hospitals other than the public ones.

\section{Declarations}

Ethics approval and consent to participate: Ethical approvals for this study were granted by the Vice-Chancellor in Research AffairsTehran University of Medical Sciences (IR. TUMS. VCR. REC. 1398.360), in addition, the study was submitted to the ethics committee local to our study in Palestine, Helsinki committee in the Palestinian Health Research Council, approved and given the code: (PHRC/HC/959/19). Moreover, informed consents were verbally obtained out from all participants, and confidentiality was assured as well.

Consent for publication: Not applicable.

Availability of data and materials: The datasets used and/or analyzed during the current study are available from the corresponding author on reasonable request.

Competing interests: The authors declare that they have no competing interests.

Funding: This study was partially funded by Tehran University of Medical Sciences as a requirement for PhD degree.

Authors' contributions: Firstly, it should be noted that all authors read and approved the manuscript.

IS, EJP and AAS was responsible for conception, design, and drafting the work.

IS, MH and AES was accountable for analysis and substantive revision of the work.

EJP, MH, AES and AAS was responsible in interpretation and substantive revision of the work.

In addition, IS, AAS have approved the submitted work, and they are personally accountable for the author's own contributions and to ensure that questions related to the accuracy or integrity of any part of the work.

Acknowledgments: The authors would like to thank all data collectors and highly appreciate their efforts in this original research work.

\section{References}

1. Coulter A, Jenkinson C. Health Services Research European patients ' views on the responsiveness of health systems and healthcare providers. 2005;15(4):355-360. doi:10.1093/eurpub/cki004.

Page $14 / 16$ 
2. World Health Organization. The World Health Report 2000: Health Systems: Improving Performance. Geneva. PP - Geneva: World Health Organization; 2000. https://apps.who.int/iris/handle/10665/42281.

3. Chao J, Lu B, Zhang H, Zhu L, Jin H, Liu P. Healthcare system responsiveness in Jiangsu Province, China. BMC Health Serv Res. 2017:1-7. doi:10.1186/s12913-017-1980-2.

4. De Silva A, Valentine N. Measuring responsiveness: results of a key informants survey in 35 countries. 2000. https://apps.who.int/iris/handle/10665/67781.

5. Murray CJL, Frenk J, Policy WHOGP on E for H. A WHO framework for health system performance assessment. 1999. https://apps.who.int/iris/handle/10665/66267.

6. Gostin LO, Hodge JG, Valentine N, Nygren-Krug H, Organization WH. The domains of health responsiveness: a human rights analysis. Heal Hum rights Work Pap Ser. 2003. https://apps.who.int/iris/handle/10665/73926.

7. Bazzaz MM, Reza M, Taghvaee E, Salehi M. Health System's Responsiveness of Inpatients. Hospitals of Iran. 2015;7(7):106-13. doi:10.5539/gjhs.v7n7p106.

8. Valentine N, De Silva A, Murray C. Estimating Responsiveness Level and Distribution for 191 Countries: Methods and Results. Citeseer; 2000.

9. Valentine N, Darby C, Bonsel GJ. Which aspects of non-clinical quality of care are most important? Results from WHO's general population surveys of "'health systems responsiveness"' in 41 countries. 2008;66. doi:10.1016/j.socscimed.2007.12.002.

10. Ministry of Health. General Annual Report. Gaza; 2018.

11. Ministry of Health. Annual Report of Hospitals' Performance in Gaza Strip - Palestine. Gaza; 2018.

12. Daniel WW. Biostatistics: A Foundation for analysis in the health sciences, 7th edR Wiley. New York. 1999.

13. Ughasoro M, Okanya O, Uzochukwu B, Onwujekwe O. An Exploratory Study of Patients ' Perceptions of Responsiveness of Tertiary Health-care Services in Southeast Nigeria: A Hospital-Based Cross-Sectional Study. 2017:267-273. doi:10.4103/11193077.183255.

14. Tamimi F. Effectiveness of using the Quality Management System (ISO 9001) in improving the performance and administrative units of the Ministry of Education in Jordan from the viewpoint of its employees and the degree of their satisfaction with this system. 2004.

15. Valentine NB, Silva A, De, Kawabata K, Darby C, Murray CJL, Evans DB. Health System Responsiveness: Concepts, Domains and Operationalization. 2014;(August).

16. Javadi M, Karimi S, Raiesi A, Yaghoubi M, Kaveh K. Comparison of patients' and nurses' viewpoints about responsiveness among a sample from public and private hospitals of Isfahan. 2011.

17. Ebrahimipour H, Vafaei Najjar A, Khani Jahani A, et al. Health System Responsiveness: A Case Study of General Hospitals in Iran. Int J Heal Policy Manag. 2013;1(1):85-90. doi:10.15171/ijhpm.2013.13.

18. Mohammadi A, Koorosh K. Responsiveness in the Healthcare Settings: A Survey of Inpatients. 2014;3(3):123-132.

19. Fiorentini G, Robone S, Verzulli R. How do hospital - specialty characteristics influence health system responsiveness ? An empirical evaluation of in - patient care in the Italian region of Emilia - Romagna. 2017;(May):1-16. doi:10.1002/hec.3540.

20. Adesanya T, Gbolahan O, Ghannam O, et al. Exploring the responsiveness of public and private hospitals in Lagos, Nigeria. $2012 ; 1$.

21. Peltzer K, Phaswana-mafuya N. Patient experiences and health system responsiveness among older adults in South Africa. 2012;1.

22. Kashkoli SA, Zarei E, Daneshkohan A, Khodakarim S. Hospital responsiveness and its effect on overall patient satisfaction: A cross- sectional study in Iran. Int J Health Care Qual Assur. 2016.

23. Najafı F, Karami-matin B, Rezaei S, Rajabi-gilan N. Health system responsiveness after health sector evolution plan (HSEP): An inpatient survey in Kermanshah in 2015. 2016.

24. Mosallam RA, Aly MM, Moharram AM. Responsiveness of the health insurance and private systems in Alexandria, Egypt. 2013:46-51. doi:10.1097/01.EPX.0000427042.54093.c4.

25. Bazzaz MM, Taghvaee MRE, Salehi M, Bakhtiari M, Shaye ZA. Health System's Responsiveness of Inpatients: Hospitals of Iran. Glob J Health Sci. 2015;7(7):106-13. doi:10.5539/gjhs.v7n7p106.

26. Mosallam RA, Aly MM, Moharram AM. Responsiveness of the health insurance and private systems in Alexandria, Egypt. J Egypt Public Health Assoc. 2013;88(1):46-51. doi:10.1097/01.EPX.0000427042.54093.c4.

Page $15 / 16$ 
27. Karami F, Moradi-lakeh M, Fallah-Abadi H, Nojomi M. Health System Responsiveness for Care of Patients with Heart Failure: Evidence form a University Hospital. 2014;17(11):736-740.

28. Sajjadi F, Moradi-lakeh M, Nojomi M, Baradaran HR, Azizi F. Health system responsiveness for outpatient care in people with diabetes Mellitus in Tehran. 2015.

29. Marhamati T, Torkzahrani S, Nasiri M, Lotfi R. The examination of quality of pregnancy care based on the World Health Organization's "Responsiveness" model of selected pregnant women in Tehran. 2017;(February):3720-3727.

30. Mohammed S, Bermejo JL, Souares A, Sauerborn R, Dong H. Assessing responsiveness of health care services within a health insurance scheme in Nigeria: users ' perspectives. 2013.

\section{Supplementary Files}

This is a list of supplementary files associated with this preprint. Click to download.

- InterviewbasedQuestionnaire.pdf 